\title{
Prolonged enhancement of cytotoxic T lymphocytes in the post-recovery state of severe COVID-19
}

\author{
Yumi Mitsuyama ${ }^{1}$, Kazuma Yamakawa ${ }^{2 *}$, Katsuhide Kayano², Miho Maruyama', Takeshi Wada ${ }^{3}$ and \\ Satoshi Fujimi ${ }^{1}$
}

\begin{abstract}
We evaluated the peripheral blood immune responses of lymphocytes in severe Coronavirus disease 2019 (COVID-19) patients in different stages of recovery using single-cell mass cytometry. The patients with prolonged hospitalization did not show recovery of B lymphocyte counts and CD4-positive T lymphocyte counts but did show abundant CD8positive T lymphocytes. CD4 and CD8 T cells expressing high levels of T-bet and Granzyme B were more abundant in post-recovery patients. This study showed that cytotoxic Th1 and CD8 T cells are recruited to the peripheral blood long after recovery from COVID-19.
\end{abstract}

Keywords: COVID-19, Post-recovery, Single-cell mass cytometry, T-bet, Granzyme B, Cytotoxic T lymphocytes

\section{Dear Editor,}

The pandemic of coronavirus disease 2019 (COVID-19) is a global public health emergency. Several studies have reported a complex network of peripheral blood immune responses in patients with COVID-19 [1]. However, very little is known about immune cell alterations in critically ill patients who have recovered from COVID-19.

We profiled the characteristic peripheral cellular profiles of patients with COVID-19 using single-cell mass cytometry (cytometry by time-of-flight: CyTOF). Peripheral blood mononuclear cells (PBMCs) of six patients who recovered from severe COVID-19, three of whom were discharged (recovered patients: RP) and three who required prolonged hospitalization (hospitalized patients: $\mathrm{HP}$ ) at the time of blood sampling, were compared with those of healthy donors (HD) (Table 1). Patients' blood samples were collected about 3 months after admission.

\footnotetext{
*Correspondence: kazuma.yamakawa@ompu.ac.jp

${ }^{2}$ Department of Emergency Medicine, Osaka Medical

and Pharmaceutical University, 2-7 Daigakumachi, Takatsuki, Osaka 569-8686, Japan

Full list of author information is available at the end of the article
}

A 43-marker antibody panel was used for CyTOF staining of PBMCs, which were analyzed on a Helios mass cytometer (Fluidigm Sciences Inc.). We identified seven cell subsets and visualized the changes in the cell populations of all samples on a t-distributed Stochastic Neighbor Embedding (t-SNE) map (Fig. 1A). For comparison of the three groups, data were concatenated within a group and the cell distribution was visualized on a t-SNE map (Fig. 1B). The contour density of B lymphocytes was lower in the HP group than that in the HD group, whereas that in the RP group had recovered to the same level as that in the HD group. CD4-positive T lymphocytes were fewer in the HP group, followed by the RP group, whereas CD8-positive T lymphocytes were more abundant in the RP and HP groups versus HD group. Natural killer (NK) cells were more abundant in the HP group, followed by the HD group, and were less frequent in the RP group. The frequency of protein expression inside and outside the cells of all samples is shown in the histogram (Fig. 2A). The data for each group were concatenated (Fig. 2B). CD4 T cells showing high expression of T-bet and Granzyme B were more abundant in the HP original author(s) and the source, provide a link to the Creative Commons licence, and indicate if changes were made. The images or other third party material in this article are included in the article's Creative Commons licence, unless indicated otherwise in a credit line to the material. If material is not included in the article's Creative Commons licence and your intended use is not permitted by statutory regulation or exceeds the permitted use, you will need to obtain permission directly from the copyright holder. To view a copy of this licence, visit http://creativecommons.org/licenses/by/4.0/. The Creative Commons Public Domain Dedication waiver (http://creativeco mmons.org/publicdomain/zero/1.0/) applies to the data made available in this article, unless otherwise stated in a credit line to the data. 


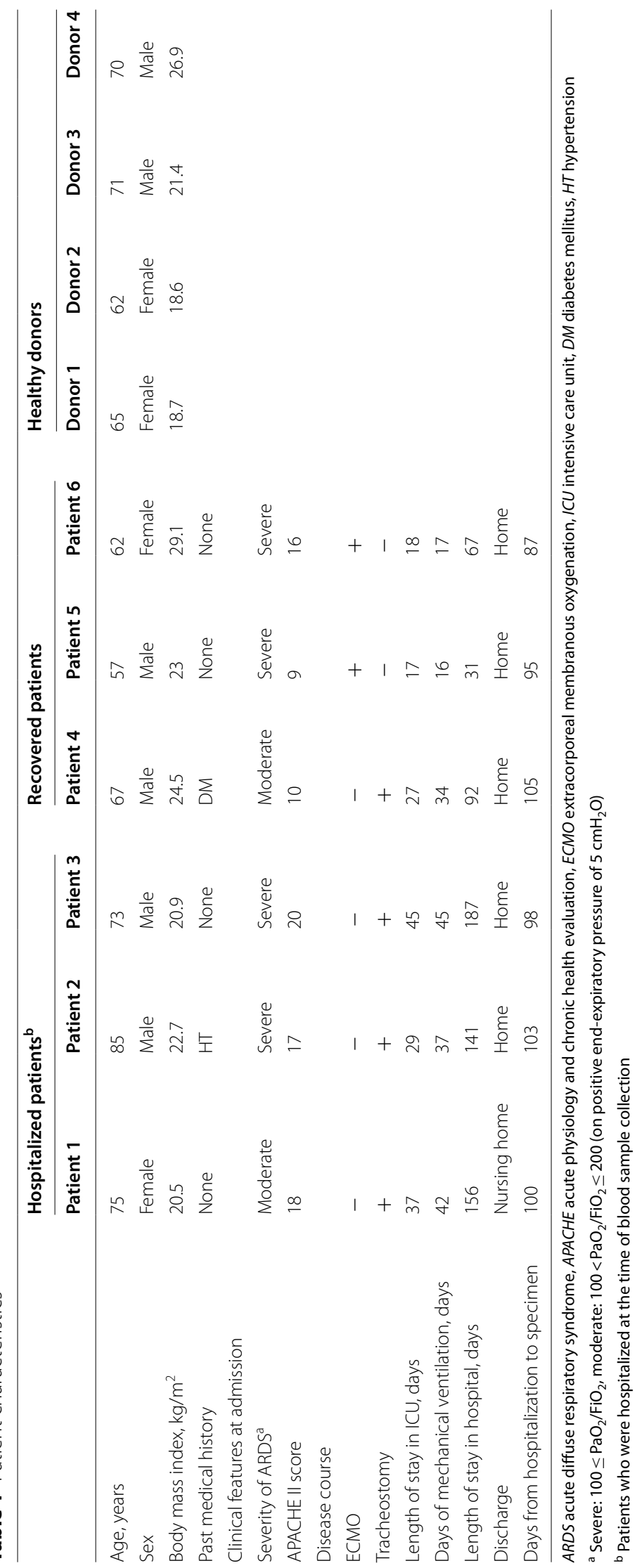




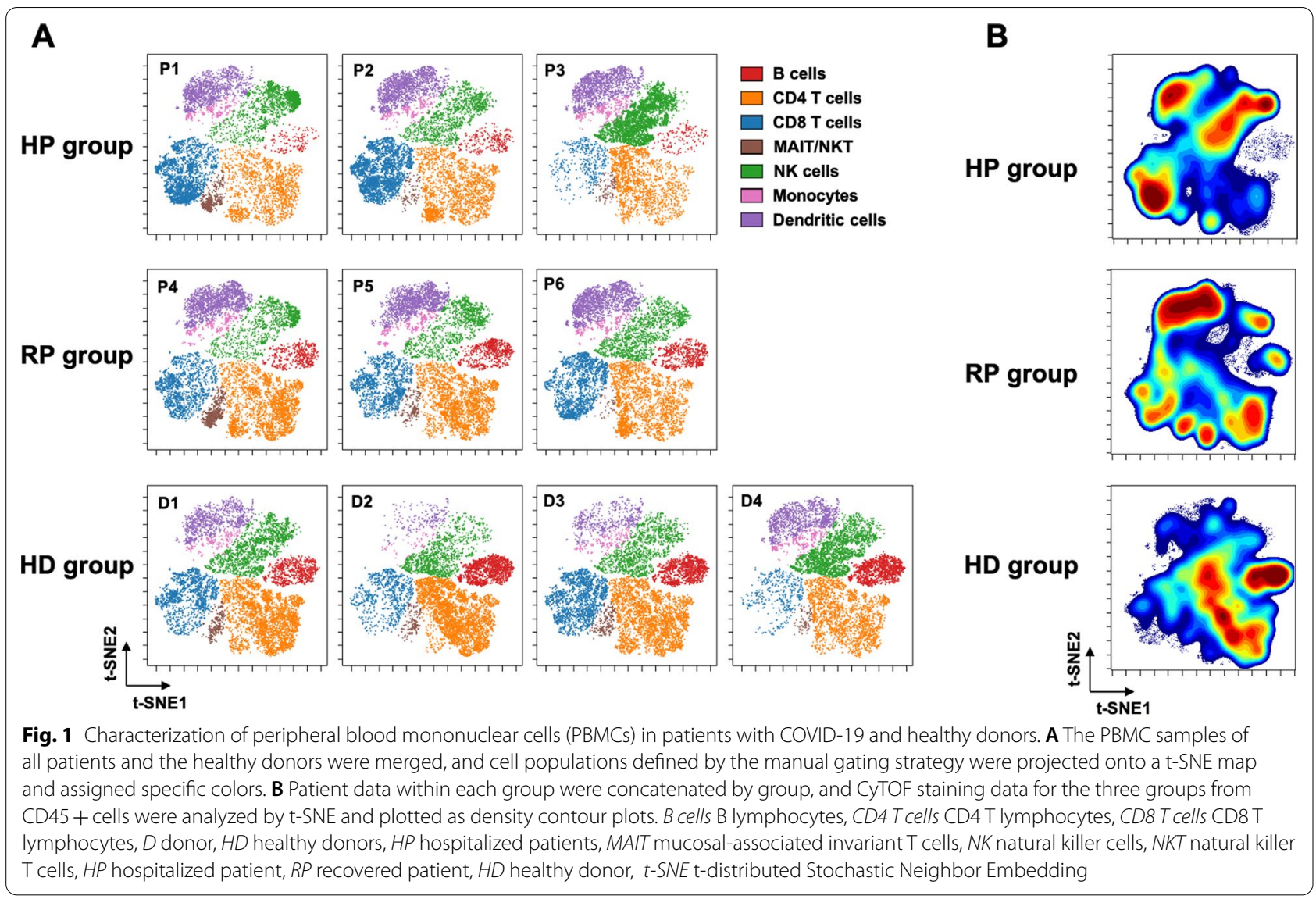

group, followed by the RP group. The number of CD8 T cells highly expressing T-bet and Granzyme B was also higher in the HP and RP groups (Fig. 2C).

We have shown the peripheral blood immune responses of lymphocytes and NK cells in severe COVID19 patients in different stages of recovery. It has been reported that especially regarding B lymphocyte counts, lymphopenia of patients with acute-phase COVID-19 recovers after polymerase chain reaction tests become negative [2]. Our results suggest that long-term recovery of B lymphocytes might be related to the severity of illness and the current stage of recovery. The NK cell population is reported to be greatly altered in patients with acute COVID-19, with an expansion of the cytokine-producing NK cells and a decrease in the cytolytic NK cells responsible for innate immunity [3]. Although cytolytic NK cells recovered with improvement of the disease, the frequency of cytokine-producing NK cells remained elevated in severe COVID-19. Elevated cytokine-producing NK cells may lead to impaired NK cell cytotoxicity and decreased regulation of cellular and humoral adaptive immune responses [4].

T-bet is the master transcription factor of CD4 T helper type 1 (Th1) cells and plays a major part in protective immunity in cooperation with CD4, CD8 T cells and natural killer T (NKT) cells [5]. Granzyme B is mainly expressed on activated memory CD8 and memory CD4 T cells, NK cells and NKT cells during infection and inflammation, and has important roles in promoting removal of virus-infected cells by cytotoxic $\mathrm{T}$ cells and in suppressing the host immune response [6]. Therefore, the high expression of T-bet and Granzyme B in CD4 and CD8 T cells indicates increased cytotoxicity of lymphocytes. Previous reports showed that cytotoxicity is enhanced in CD4 and CD8 T cells in the acute phase of severe COVID-19, and the elevation in cytotoxic CD8 $\mathrm{T}$ cell counts persists after recovery $[7,8]$. The present study also revealed that the persistence of $\mathrm{T}$ cells highly expressing T-bet and Granzyme $\mathrm{B}$ in the recovered COVID-19 patients might indicate prolonged suppression of the immune response and an unrecovered inflammatory process. Comparing the RP and HP groups, although recovery of $B$ lymphocytes was restored in the RP group, the recruitment of cytotoxic $\mathrm{T}$ cells to the peripheral blood persisted in both post-COVID-19 groups. This may suggest that the activation of cellular immunity is more prolonged than that of humoral immunity in COVID-19, depending on the severity of 

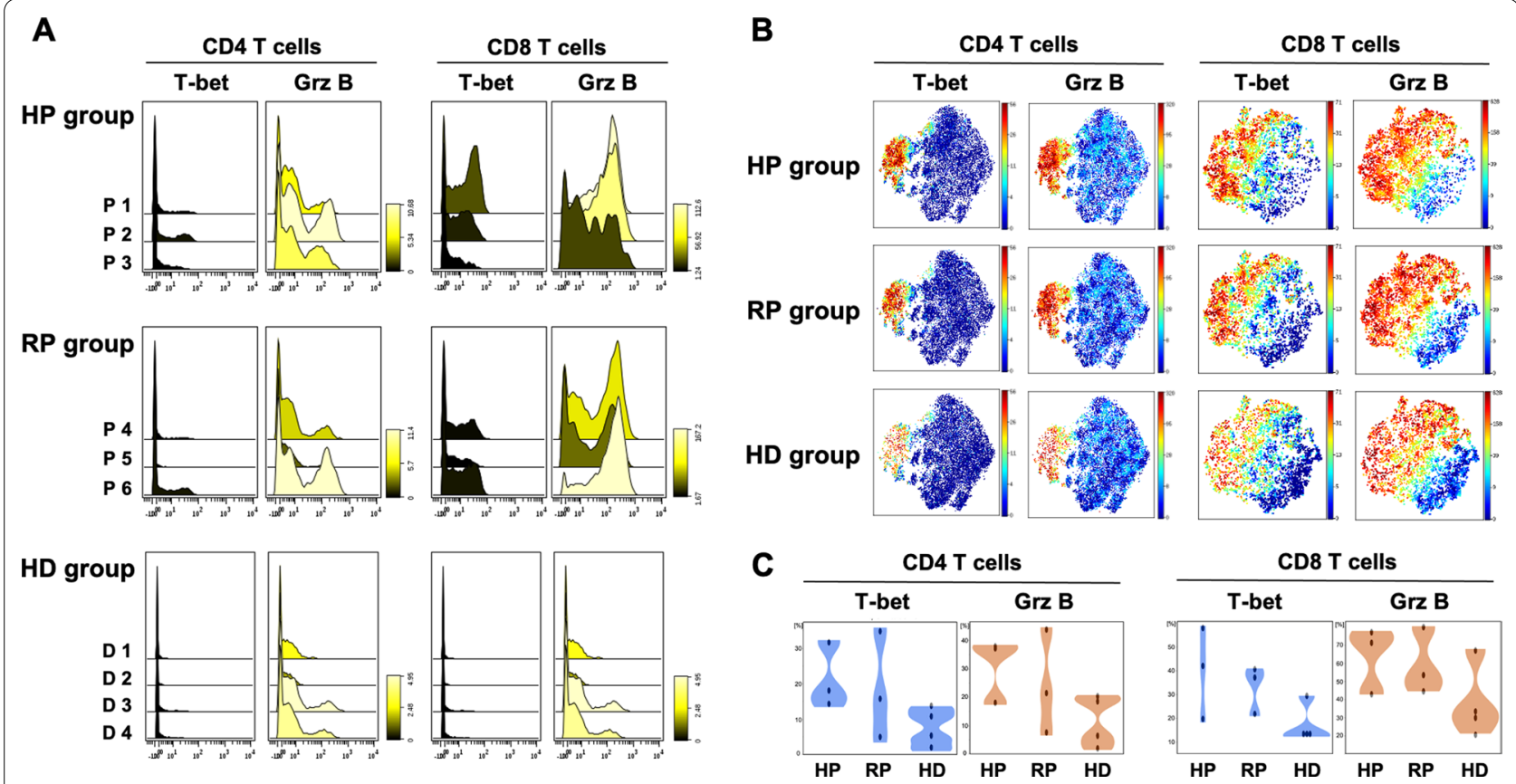

Fig. 2 Expression of T-bet and Granzyme B on CD4 and CD8 T cells in patients with COVID-19 and healthy donors. A Histograms showing relative changes in expression intensities of the indicated markers on CD4 and CD8 T cells from the PBMCs of the patients and healthy donors. The color bar legend indicates differences in marker expression levels: yellow (increased) or black (decreased). B t-SNE projections of CD4 and CD8 T cells from the HP, RP and HD groups generated by concatenating patient data within each group for the indicated cell markers. CViolin plots showing the percentage of cells expressing the indicated markers in the three groups. The plots show the distribution of sample values. CD4T cells CD4 T lymphocytes, CD8 T cells CD8 T lymphocytes, Grz B granzyme B, HD healthy donor, HP hospitalized patient, PMBCs peripheral blood mononuclear cells, RP recovered patient, $t S N E$ t-distributed Stochastic Neighbor Embedding

the illness and the stage of recovery. These results suggest that restoration of immune homeostasis after COVID-19 may require a long time and that complications, such as secondary infections during the recovery process need to be addressed. Thus, the prolonged cytotoxicity of lymphocytes after recovery from COVID-19 may have implications for elucidation of the long-term changes in immune responses after COVID-19.

\section{Abbreviations}

COVID-19: Coronavirus disease 2019; CyTOF: Cytometry by time-of-flight; NK cells: Natural killer cells; NKT cells: Natural killer T cells; PBMCs: Peripheral blood mononuclear cells; t-SNE: t-distributed Stochastic Neighbor Embedding; Th1: Thelper type 1.

\section{Acknowledgements}

None.

\section{Authors' contributions}

YM and $\mathrm{KY}$ undertook study design; $\mathrm{YM}$ enrolled patients and acquired data; KK and MM processed patient samples. KK performed CyTOF. YM, KY, TW and SF drafted the manuscript and revised it critically. KY organized and supervised the conduction of the study. All authors read and approved the final manuscript.

\section{Funding}

This work was supported by grants from the Ministry of Education, Culture, Sports, Science and Technology, Japan (19H03759).

\section{Availability of data and materials}

The datasets analyzed during the current study are available from the corresponding author on reasonable request.

\section{Declarations}

\section{Ethics approval and consent to participate}

The study was approved by the Institutional Review Board of Osaka General Medical Center [approval number: C201912002]. Written informed consent was obtained from all patients.

\section{Consent for publication}

Not applicable.

\section{Competing interests}

The authors declare that they have no competing interests.

\section{Author details}

${ }^{1}$ Division of Trauma and Surgical Critical Care, Osaka General Medical Center, Osaka, Japan. ${ }^{2}$ Department of Emergency Medicine, Osaka Medical and Pharmaceutical University, 2-7 Daigakumachi, Takatsuki, Osaka 569-8686, Japan.

${ }^{3}$ Division of Acute and Critical Care Medicine, Department of Anesthesiology and Critical Care Medicine, Faculty of Medicine, Hokkaido University, Sapporo, Japan.

Received: 18 September 2021 Accepted: 7 December 2021

Published online: 20 December 2021 


\section{References}

1. Stephenson E, Reynolds G, Botting RA, Calero-Nieto FJ, Morgan MD,

Tuong ZK, et al. Single-cell multi-omics analysis of the immune response in COVID-19. Nat Med. 2021;27:904-16.

2. Kuri-Cervantes L, Pampena MB, Meng W, Rosenfeld AM, Ittner CAG, Weisman AR, et al. Comprehensive mapping of immune perturbations associated with severe COVID-19. Sci Immunol. 2020;5(49):7114.

3. Leem G, Cheon S, Lee H, Choi SJ, Jeong S, Kim ES, et al. Abnormality in the NK-cell population is prolonged in severe COVID-19 patients. J Allergy Clin Immunol. 2021;148(4):996-1006.e18.

4. Market M, Angka L, Martel AB, Bastin D, Olanubi O, Tennakoon G, et al. Flattening the COVID-19 curve with natural killer cell based immunotherapies. Front Immunol. 2020;11:1512

5. Pritchard GH, Kedl RM, Hunter CA. The evolving role of T-bet in resistance to infection. Nat Rev Immunol. 2019;19(6):398-410.

6. Afonina IS, Cullen SP, Martin SJ. Cytotoxic and non-cytotoxic roles of the CTL/NK protease granzyme B. Immunol Rev. 2010;235(1):105-16.

7. Meckiff BJ, Ramírez-Suástegui C, Fajardo V, Chee SJ, Kusnadi A, Simon H, et al. Imbalance of regulatory and cytotoxic SARS-CoV-2-reactive CD4+ T cells in COVID-19. Cell. 2020;183(5):1340-53.e16.

8. Shuwa HA, Shaw TN, Knight SB, Wemyss K, McClure FA, Pearmain L, et al. Alterations in T and B cell function persist in convalescent COVID-19 patients. Med (N Y). 2021;2(6):720-35.e4

\section{Publisher's Note}

Springer Nature remains neutral with regard to jurisdictional claims in published maps and institutional affiliations.

- fast, convenient online submission

- thorough peer review by experienced researchers in your field

- rapid publication on acceptance

- support for research data, including large and complex data types

- gold Open Access which fosters wider collaboration and increased citations

- maximum visibility for your research: over $100 \mathrm{M}$ website views per year

At $B M C$, research is always in progress.

Learn more biomedcentral.com/submissions 